\title{
Artificial neural network modelling of cutting force components in milling
}

\author{
Ireneusz Zagórski ${ }^{1}$, Monika Kulisz $^{2,}$, and Aleksandra Semeniuk $^{3}$ \\ ${ }^{1}$ Lublin University of Technology, Faculty of Mechanical Engineering, Department of Production Engineering, Nadbystrzycka 36, \\ 20-618 Lublin, Poland, \\ ${ }^{2}$ Lublin University of Technology, Faculty of Management, Department of Organisation of Enterprises, Nadbystrzycka 38 , \\ 20-618 Lublin, Poland \\ ${ }^{3}$ Lublin University of Technology, Faculty of Mechanical Engineering, Nadbystrzycka 36, 20-618 Lublin, Poland
}

\begin{abstract}
The following paper will give an account of experimental tests and simulation of the cutting force components Fx, Fy and Fz in down milling of AZ91D magnesium alloy. The milling operation employed two milling cutters with a different helix angle, $\lambda \mathrm{s}=20^{\circ}$ and $\lambda \mathrm{s}=50^{\circ}$, and was conducted with changeable milling machining parameters: cutting speed, feed per tooth, axial depth of cut. The simulation part of the study was conducted in Statistica software environment with the application of Multi-Layered Perceptron neural network architecture, and using a "black box" approach, which guarantees a good fit of input and output data obtained from the experimental tests.
\end{abstract}

\section{Introduction}

Manufacturing innovative modern components of machines and devices for the aircraft and automotive industries requires using state-of-the-art engineering materials and effective machining methods, such as milling with advanced tools and machining centres. The ever-increasing challenges of the modern market may generate serious production costs, therefore, engineers and manufacturers must seek to increase the costeffectiveness of production without compromising the quality of the final product. In subtractive machining optimisation may be achieved by means of analysis of the actual cutting forces and computer simulation. The combined data obtained from such analyses may improve the stability and effectiveness of machining. Artificial neural network simulation aids cost optimisation through reducing the number of actual iterations regarding the specification and optimisation of technological parameters of machining, and is moreover an effective tool for minimising machining errors.

\section{The state of knowledge}

Subtractive machining lies at the heart of machine building and should therefore by characterised by high productivity, efficiency, and effectiveness of subsequent machining layers removal. Milling and High Speed Milling are important representatives of subtractive machining. Qualitative description of these operations frequently employs machinability factors.

The cutting forces occurring in milling constitute the practical machinability factors. A sudden increase in the volume of cutting forces may result in undesirable machined surface errors. The total cutting force is a resultant of a number of factors, including: the material of the cutting tool and workpiece, or the cutting tool geometry; however, these are machining parameters that are of critical importance to the cutting forces. Machining with high cutting speeds, feeds or depths of cut contributes to increasing the productivity of milling [1-2]. The paper [3] presents the research results of the influence of technological parameters on the values and course of the radial force during brushing process. Based on the research it was found that the radial force increases with the increase of the brushing speed and brush stiffness. Analysis of the cutting force components is essential particularly in aircraft and medical applications, where the machined components require ultra-high precision, and involve thin-walled features of intricate geometry [4]. Excessive cutting forces may have an adverse effect on the quality of machined surfaces, which results from the increased level of vibration in the milling machine-milling cutterworkpiece-fixture system [5].

Other factors that have an impact on the total cutting force are adhesion and the built-up edge. They may lead to significant fluctuations in the values of the cutting force components in milling, deterioration of the machined surface quality and of the dimensional and shape accuracy of the workpiece [6]. Cutting speed $v_{c}$ is the parameter which to a considerable extent determines the cutting force and productivity of milling. According to cutting speed milling operations may be classified into conventional and high speed milling (HSM). The range of HSM parameters may be defined as $\partial F / \partial v_{c}<0$ whereas $\partial F / \partial v_{c}>0$ determines the range of speeds of conventional

\footnotetext{
Corresponding author: m.kulisz@pollub.pl
} 
machining. It is accepted that what distinguishes HSM from conventional machining is that in HSM the increase in the cutting speed $v_{c}$ leads to the decrease of the cutting forces [7]. Alternatively, HSM may be understood as a high-performance cutting method which produces high-quality machined surface, eliminates the need for finishing operations, traditionally realised through e.g. grinding and polishing.

Research studies in the field also focus on the effect of changing tool geometry on the cutting forces in milling. One of the studies analysed the changes of specific technological milling parameters $\left(v_{c}, f_{z}, a_{p}\right)$ performed with the carbide milling cutters at a different contact angle $\left(\gamma=5^{\circ}\right.$ and $\left.\gamma=30^{\circ}\right)$. Lower values of cutting force components and their amplitudes, indicating greater stability of the process, were observed for the tool $\gamma=30^{\circ}$. Increasing the axial depth of cut triggered a proportional increase in the cutting force components and their amplitudes. A change in feed per tooth provoked the increase of the cutting forces and subsequently their stabilisation [8]. In machining with Kordell geometry tools, the $F_{x}$ and $F_{y}$ components and their amplitudes rise with the increase of feed per tooth $f_{z}$. In the case of milling with cutters of traditional tool geometry, a more significant influence on cutting forces and their amplitudes is observed when changing the feed per tooth $f_{z}$ rather than cutting speed $v_{c}$. Furthermore, it ought to be remarked that the cutting force components decrease with the increase of cutting speed to $v_{c}=1200$ $\mathrm{m} / \mathrm{min}$ in traditional tool geometry $[8,13]$.

Another factor of high importance is the impact of cutting tool coating (such as the $\mathrm{TiB}_{2}$ and TiAlCN type) on the cutting forces in milling. The lowest values of the cutting forces $\left(F_{x}, F_{y}\right)$ in milling Al6082 alloy with carbide tools were obtained for a tool with $\mathrm{a}^{\mathrm{TiB}} \mathrm{Ti}_{2}$ coating. During the $v_{c}$ change, the characteristic point of „transition" to the range of HSC (where $v_{c g r}=450 \div 600$ $\mathrm{m} / \mathrm{min}$ ) was observed [9].

Research work [10] analysed, inter alia, the values and amplitudes of the cutting force $F_{x}$. The machining carried out as a part of the test was conducted with three types of milling cutters (two monolithic tools with highspeed steel or cemented carbide, and an indexable milling cutter R390-020B20-11L). The workpiece material was EN AlSi2lCuNi aluminium alloy. In tests it was determined that machining with the indexable tool was characterised by the highest increase in the cutting forces and their amplitudes. Such phenomenon is highly undesired in milling as it has a detrimental effect on tool life, machine tool life and machined surface quality. The study showed that machining performed with the cemented carbide tool exhibited superior quality in comparison with the other cutting solutions. Lower cutting force observed in that case resulted from lower cutting resistance ("sharp" tool geometry).

The indexable tool generated comparable cutting forces to that of the high-speed steel cutter. Moreover, when milling with an indexable tool the amplitude of the cutting force $F_{x}$, which is an important indicator of stability in milling, was by far the highest among the tested tools. This predominantly results from the unfavourable cutting edge geometry of the milling tool in question, low contact angles and helix angle $\left(\lambda s=5^{\circ}\right)$. Such parameters are highly undesired in machining as they generate instability and resulting increase in the amplitudes of the cutting forces.

In AZ91HP alloy milling with PCD cutter and in the presence of cutting fluid cutting forces assume low values and grow linearly with the increase of feed. Lower cutting forces translate into smaller tendency of tools to overheat (smaller coefficient of friction at a toolworkpiece interface). What can be observed along with lower cutting forces, especially as far as small cross-section of a machined layer is concerned, is a significantly lower temperature in the cutting area [6].

The arguments presented in the preceding paragraphs show that there are numerous factors that contribute to the total cutting force. The character of relationships between them is frequently non-linear, therefore we may observe a growing interest in modelling machining processes by means of mathematical methods of analysis $[1,11]$, or artificial intelligence [12].

The main purpose of milling modelling is prediction of non-linear technological processes. Its analysis can contribute to the creation of a system which could support decision-making processes in an enterprise (for instance through optimisation of milling process focusing on the selection of suitable technological parameters of machining).

For the purpose of cutting force components simulation, artificial neural network was used. The applied software was Statistica. During testing, two networks were scrutinised: RBF (Radial Basis Function) and MLP (Multi-Layered Perceptron) [13]. The authors of the work showed a simple model of milling process of two changeable machining parameters, cutting speed $v_{c}$ and feed per tooth $f_{z}$, whereas the remaining machining parameters were fixed (axial depth of cut ap, radial depth of cut $a_{e}$ and helix angle $\lambda s$ ). The obtained model enables testing different cutting speed $v_{c}$ and feed per tooth $f_{z}$ settings without the need for conducting any additional milling tests. In [14] the cutting force prediction model for circular end milling process was employed to analyse the curvature effects of tool path on chip thickness, along with the impact of entry and exit angles. Experimental results showed a good fit of measured and simulated results.

The presented brief review of selected literature in the field shows that analysis of cutting forces is of great importance to effects of milling processes. Simultaneously, the results of numerical simulation enable prediction of processes of a non-linear nature. Simulation of such processes may prove particularly significant when optimal process parameters are required in the face of a limited amount of input data available.

\section{Methodology, aim of study and research subject}

The workpiece material tested in the presented study was AZ91D magnesium alloy, whose high mechanical properties and excellent corrosion resistance determine it high applicability in different industrial applications. 
The chemical composition and properties of the alloy under analysis are presented in Table 1.

Table 1. Chemical composition and mechanical properties of AZ91D magnesium alloy [15-17].

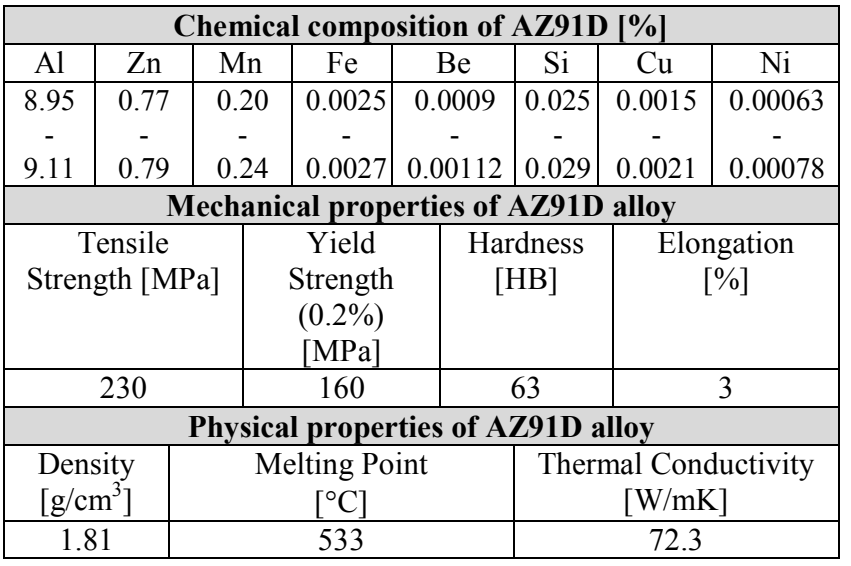

The machining operations were carried out by means of AVIA VMC 800 HS vertical machining centre controlled by Heidenhain iTNC 530 control (power $25 \mathrm{~kW}, n_{\max }$ up to $24000 \mathrm{rev} / \mathrm{min}$ and $v_{f \max }$ up to $40 \mathrm{~m} / \mathrm{min})$.

Milling operations were carried out with the solid carbide end mill with unequal helix angle, $\lambda s=20^{\circ}$ and $\lambda s=50^{\circ}$, diameter $\mathrm{d}=16 \mathrm{~mm}$, number of cutting teeth $\mathrm{z}$ $=3$. The cutting tool was mounted in the SECO HSK63A SFD 16x120 tool holder with thermal shrinkfit technology. Before the tool holder was mounted in the spindle they were balanced in CIMAT CMT-15V2N balancing machine, balancing class $G 2.5$ at 25000 $\mathrm{rev} . / \mathrm{min}$ according to ISO1940:2003, which allows to have an unbalance of $1 \mathrm{~g} \mathrm{~mm} / \mathrm{kg}$. The unbalance in our study was as follows: for the cutting tool with $\lambda s=20^{\circ}$ $0.42 \mathrm{~g} \mathrm{~mm} / \mathrm{kg}$, for the helix angle $\lambda s=50^{\circ}-0.23 \mathrm{~g}$ $\mathrm{mm} / \mathrm{kg}$. The cutting forces were measured with $927 \mathrm{~B}$ dynamometer by Kistler, operating in the range of $5 \mathrm{kN} \div 5 \mathrm{kN}$, equipped with a charge amplifier 5017B and LMS SCADAS Mobile SCM05 data acquisition hardware.

The range of changeable technological parameters of machining in tests was as follows: cutting speed $v_{c}=$ $400 \div 1200 \mathrm{~m} / \mathrm{min}$, feed per tooth $f_{z}=0.05 \div 0.3 \mathrm{~mm} /$ tooth, axial depth of cut ap $=1 \div 6 \mathrm{~mm}$. The radial depth of cut parameter $a_{\mathrm{e}}=14 \mathrm{~mm}$ was constant in all milling operations.

Given that the milling process is a type of network design then the cutting forces $F_{x}, F_{y}$ and $F_{z}$ are output units and cutting speed $v_{c}$, feed per tooth $f_{z}$ and axial depth of cut $a_{p}$ along with helix angle $\lambda s$ are input variables. The presented network employs the black box model, which ensures good performance on the training set. The black box approach was selected as it was the best to reflect the complex character of milling. Such a model is implemented when it is difficult to determine mathematical equations that would describe the analysed process [13].

The cutting forces $F_{x}, F_{y}$ and $F_{z}$ are defined in the dynamometer's system of coordinates, and these components have their counterparts in the coordinates system of the machine tool [18]:
- $F_{x}$ - feed force $\mathrm{F}_{\mathrm{f}}$

- $F_{y}$ - normal to the feed force $\mathrm{F}_{\mathrm{fn}}$,

$-F_{z}$ - reactive force $\mathrm{F}_{\mathrm{p}}$.

\section{Results of experimental tests and cutting force modelling}

The cutting forces $F_{x}, F_{y}$ and $F_{z}$ were measured throughout the milling process of AZ91D magnesium alloy with two tools of different helix angles $\lambda s\left(20^{\circ}\right.$, $50^{\circ}$ ). Presented in Figs. 1-3 are the results of measurements for constant feed per tooth $f_{z}=0.15$ $\mathrm{mm} /$ tooth and axial depth of cut $a_{p}=6 \mathrm{~mm}$. The results are visualised with the whiskers and box plot, which shows the maximum range of the cutting forces and the difference between the minimum and maximum values.

In certain cases we may observe outliers and extremes, which result from the increase in the cutting forces on the cutting tool entry into and exit from the workpiece.

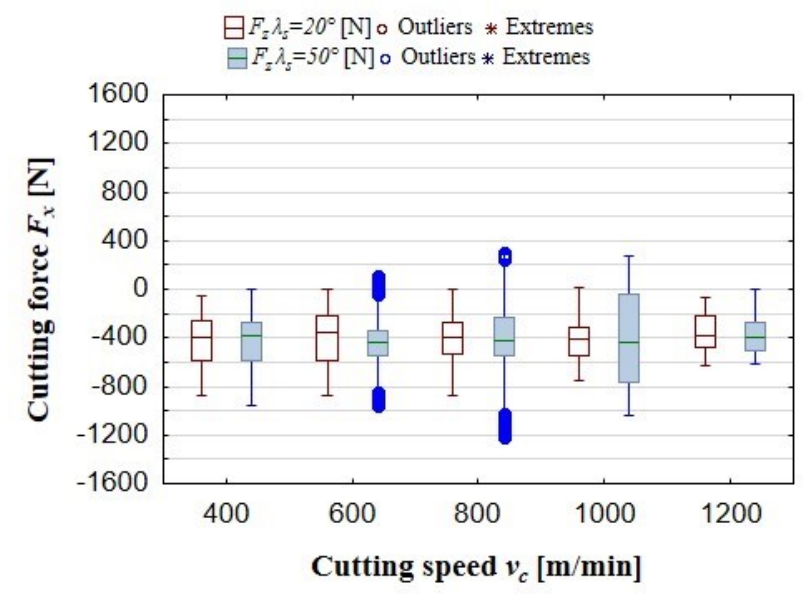

Fig. 1. Effect of cutting speed $v_{c}$ on the cutting force $F_{x}, f_{z}=$ $0.15 \mathrm{~mm} /$ tooth, $a_{p}=6 \mathrm{~mm}$.

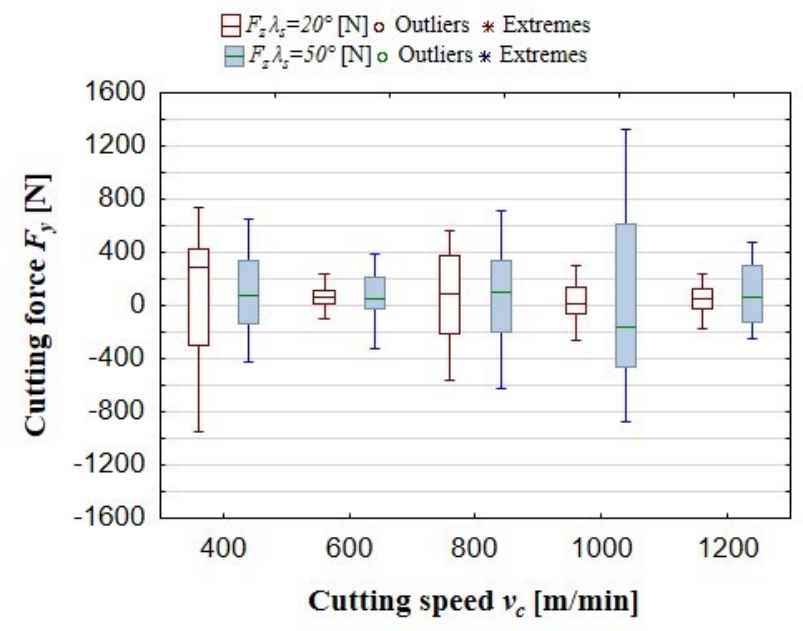

Fig. 2. Effect of cutting speed $v_{c}$ on the cutting force $F_{y}, f_{z}=$ $0.15 \mathrm{~mm} /$ tooth, $a_{p}=6 \mathrm{~mm}$. 


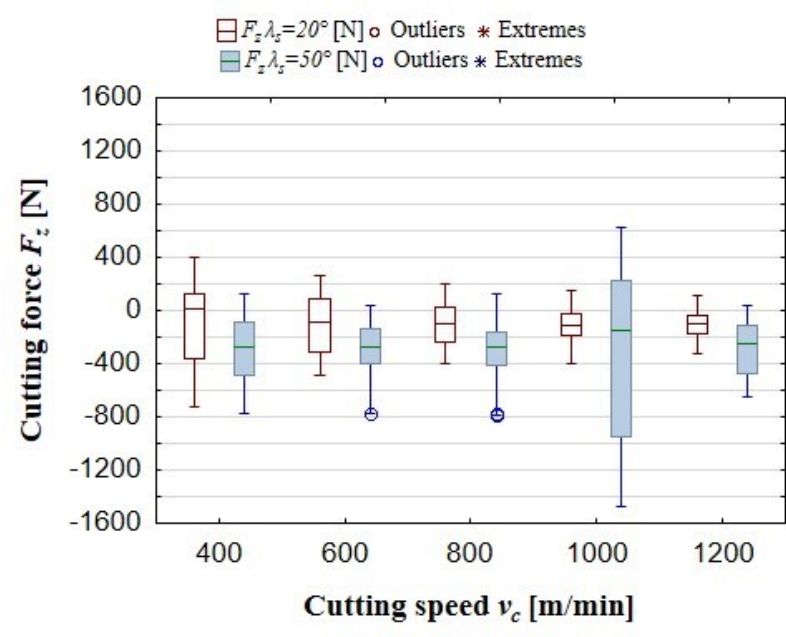

Fig. 3. Effect of cutting speed $v_{c}$ on the cutting force $F_{z}, f_{z}=$ $0.15 \mathrm{~mm} /$ tooth, $a_{p}=6 \mathrm{~mm}$.

The highest amplitude/range of the $F_{x}$ (Fig. 1) is observed in milling with the cutting speed of $800 \mathrm{~m} / \mathrm{min}$, by means of the tool with helix angle $\lambda s$ equal to $20^{\circ}$, which denotes the highest tool stability range. The cutting force component $F_{y}$ (Fig. 2) exhibits the highest range at the cutting speed of $1000 \mathrm{~m} / \mathrm{min}$, when machined with the cutting tool of helix angle of $\lambda s=50^{\circ}$. The cutting speeds which provide a better stability of milling process are $v_{c}=600 \mathrm{~m} / \mathrm{min}$ and $v_{c}=1200 \mathrm{~m} / \mathrm{min}$, with milling cutter helix angle of $\lambda s=20^{\circ}$. The reactive cutting force $F_{z}$ (Fig. 3) shows the highest amplitude at $v_{c}=1000 \mathrm{~m} / \mathrm{min}$, when machined with a cutting tool with a helix angle $\lambda s=50^{\circ}$. In the case of a lower helix angle, $\lambda s=20^{\circ}$, the range of the cutting force $F_{z}$ decreases with the decrease of cutting speed $v_{c}$.

The comparison of both tools applied in the study indicates that the cutting tool with a helix angle $\lambda s=50^{\circ}$ generates higher cutting forces. Machining magnesium alloys with this cutting tool is characterised by decreasing cutting force components $F_{x}, F_{y}, F_{z}$ at the cutting speed of $v_{c}=1200 \mathrm{~m} / \mathrm{min}$. In milling with this type of tool this is the cutting force Fx which dominates. In order to decrease the $\mathrm{Fx}$ the magnesium alloy workpiece should be machined with the cutting speed $v_{c}$ $=1200 \mathrm{~m} / \mathrm{min}$. The recommended range of feed per tooth in the case is $0.15 \div 0.3$ [mm/tooth].

The cutting forces obtained from the milling of AZ91D magnesium alloy provided the input data for the artificial network simulation. The simulation was conducted with Statistica Neural Network software using MLP (Multi-Layered Perceptron).

The key parameters of a good fit of input/output data are: training quality, validation quality and the training error determined with the least squares method. The simulations of the cutting forces $F_{x}, F_{y}$ and $F_{z}$ were conducted for two tool cutting tool helix angles $\lambda s=20^{\circ}$ and $\lambda s=50^{\circ}$. As a result 6 models were obtained. An example of the cutting force $F_{x}$ simulation is shown in Fig. 4. The network architecture for other cutting force components models is analogical, and the produced output of the network is the corresponding cutting force.

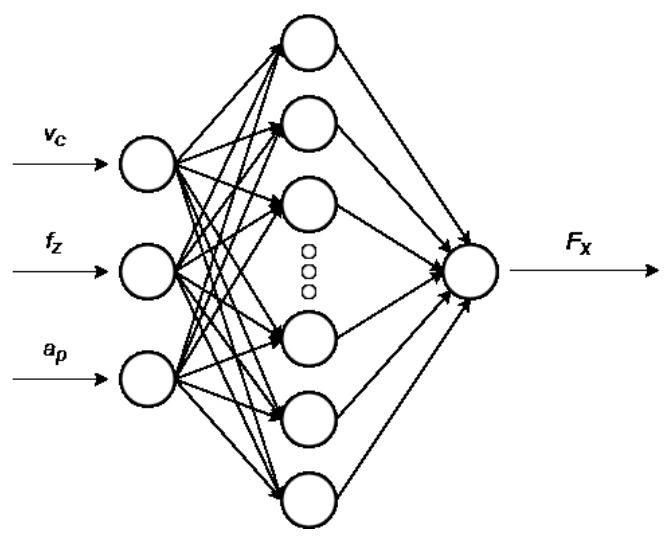

Fig. 4. Artificial neural network architecture.

It was established that the obtained neural network architecture should be simplest; hence, it contained one hidden layer. The input layer consists of three neurons (cutting speed $v_{c}$, feed per tooth $f_{z}$ and axial depth of cut $a_{p}$ ), and the output layer is one neuron (a respective cutting force component $F_{x}, F_{y}$ or $F_{z}$ ). The number of training epochs was defined experimentally in the range of $100 \div 200$, whereas the range of hidden neurons $1 \div 10$. The MLP network was trained with the use of BFGS (Broyden-Fletcher-Goldfarb-Shanno) technique. This is one of the recommended network training techniques as it offers the best performance in reducing the function to a desired level. The implemented activation functions were: linear, exponential, logistic and hyperbolic (tanh). The networks were trained for the total of 17 machining parameter sets. $80 \%$ of the results from milling test were used as the training data set whereas the remaining $20 \%$ built the validation set. Given the small number of data sets, the test data set was omitted [19].

In each simulation 100 networks were trained and the best three models were determined. The criteria for the selection of the best networks were mentioned earlier and included: training quality, validation quality, the lowest training error. Network parameters for the particular cutting forces $F_{x}, F_{y}, F_{z}$ and the cutting tool helix angle of $\lambda s=20^{\circ}$ in milling of AZ91D magnesium alloy are collated in Table 2 .

The analysis of the neural network architectures indicates that the best network for modelling the cutting force component $F_{x}$ is network 2 (MLP 3-4-1 with 4 neutrons) as the training and validation quality amounted to $99.98 \%$ and $98.57 \%$ respectively, and the training error value amounted to approx. 14N. The best network to model the cutting force $F_{y}$ is network 1 (MLP 3-7-1 with 7 neutrons), and for the cutting force component $\mathrm{Fz}$ it is network 2 (MLP 3-4-1 with 4 neutrons). The values of the cutting forces $F_{x}, F_{y}$ and $F_{z}$ obtained from the neural network models depending on cutting speed and feed per tooth are shown in Figs. 6-7.

The values of $F_{x}$ increase with the increase of feed per tooth $f_{z}$ decrease when cutting speed $v_{c}$ decreases. The same relationship is observed for the cutting force $F_{z}$. The lowest values of $F_{y}$ are obtained when the machining parameters are $v_{c}=1200[\mathrm{~m} / \mathrm{min}]$ and $f_{z}=$ $0.05 \div 0.15[\mathrm{~mm} /$ tooth $]$, and are within the range of $150 \div 200 \mathrm{~N}$. 
Table 2. Parameters of the best MLP networks for particular cutting forces, cutting tool helix angle $\lambda s=20^{\circ}$.

\begin{tabular}{|c|c|c|c|}
\hline \multicolumn{4}{|c|}{ Feed force $F_{x}$} \\
\hline Id. & 1 & 2 & 3 \\
\hline Network name & MLP 3-4-1 & MLP 3-4-1 & MLP 3-8-1 \\
\hline $\begin{array}{l}\text { Quality (training) } \\
{[\%]}\end{array}$ & 99.99 & 99.98 & 99.97 \\
\hline $\begin{array}{l}\text { Quality (validation) } \\
{[\%]}\end{array}$ & 91.1 & 98.57 & 93.8 \\
\hline Error (training) & 12.87 & 13.58 & 22.12 \\
\hline Activation (hidden) & Logistic & Logistic & Exponential \\
\hline Activation (output) & Exponential & Tanh & Logistic \\
\hline \multicolumn{4}{|c|}{ Normal to the feed force $F_{y}$} \\
\hline Id. & 1 & 2 & 3 \\
\hline Network name & MLP 3-7-1 & MLP 3-5-1 & MLP 3-6-1 \\
\hline $\begin{array}{l}\text { Quality (training) } \\
{[\%]}\end{array}$ & 99.98 & 99.96 & 99.95 \\
\hline $\begin{array}{l}\text { Quality (validation) } \\
{[\%]}\end{array}$ & 99.99 & 99.38 & 99.33 \\
\hline Error (training) & 6.41 & 15.01 & 19.46 \\
\hline Activation (hidden) & Logistic & Logistic & Tanh \\
\hline Activation (output) & Logistic & Exponential & Logistic \\
\hline \multicolumn{4}{|c|}{ Reactive force $\boldsymbol{F}_{z}$} \\
\hline Id. & 1 & 2 & 3 \\
\hline Network name & MLP 3-4-1 & MLP 3-4-1 & MLP 3-4-1 \\
\hline $\begin{array}{l}\text { Quality (training) } \\
{[\%]}\end{array}$ & 99.85 & 99.84 & 99.83 \\
\hline $\begin{array}{l}\text { Quality (validation) } \\
{[\%]}\end{array}$ & 90.78 & 99.34 & 98.97 \\
\hline Error (training) & 27.65 & 28.5 & 29.22 \\
\hline Activation (hidden) & Tanh & Logistic & Logistic \\
\hline Activation (output) & Linear & Exponential & Tanh \\
\hline
\end{tabular}

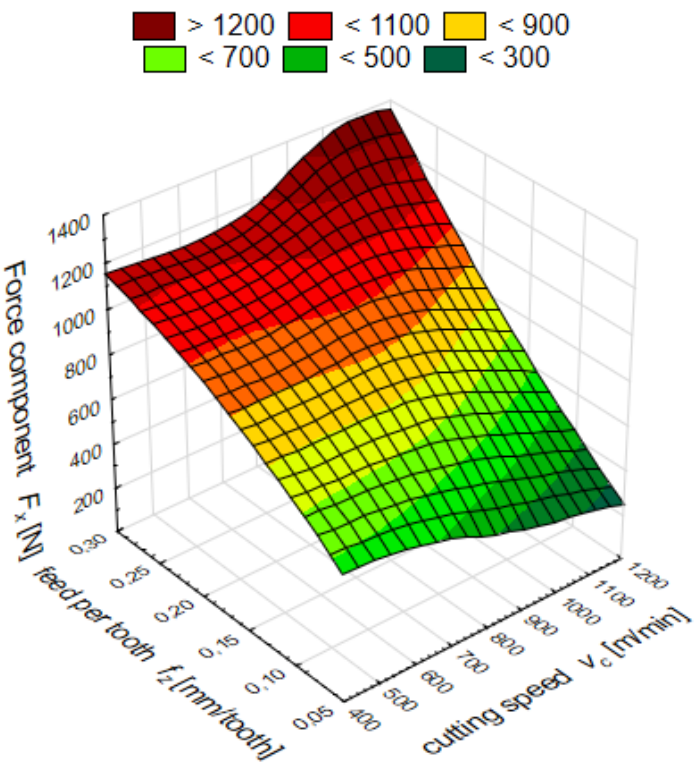

Fig. 5. Results of the cutting force $F_{x}$ simulation for cutting tool helix angle $\lambda s=20^{\circ}$, in the function of cutting speed $v_{c}$ and feed per tooth $f_{z}$ for the MLP 3-4-1 neural network architecture.

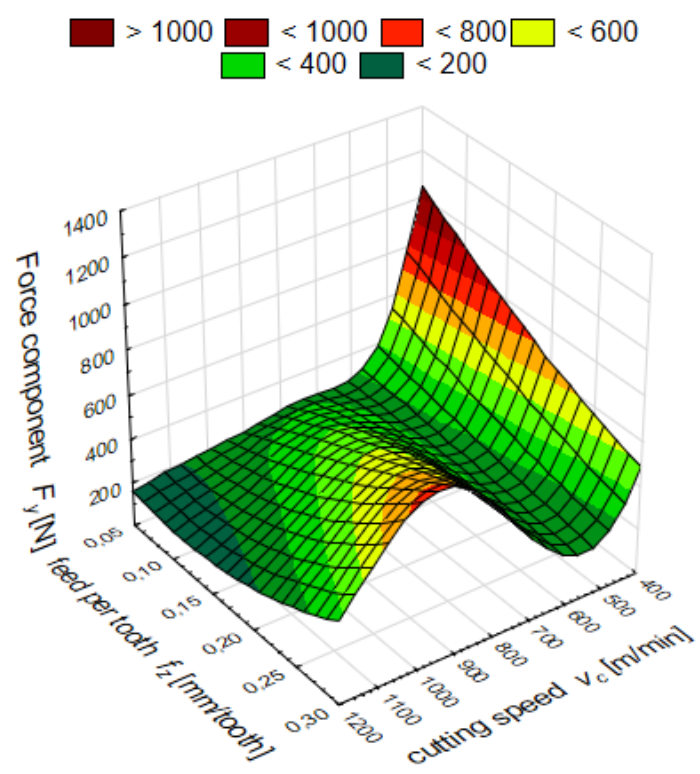

Fig. 6. Results of the cutting force $F_{y}$ simulation for cutting tool helix angle $\lambda s=20^{\circ}$, in the function of cutting speed $v_{c}$ and feed per tooth $f_{z}$, for the MLP 3-7-1 neural network architecture.
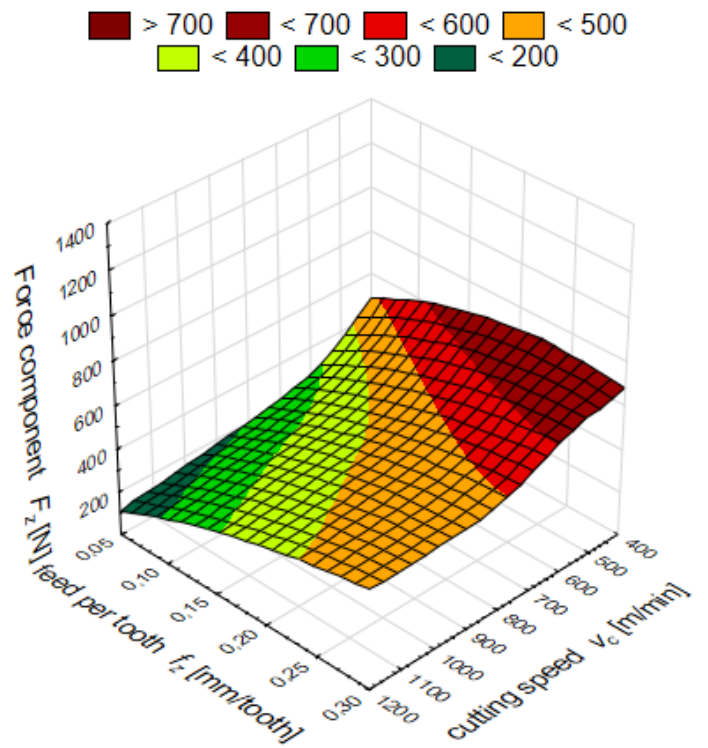

Fig. 7. Results of the cutting force $F_{z}$ simulation for cutting tool helix angle $\lambda s=20^{\circ}$, in the function of cutting speed $v_{c}$ and feed

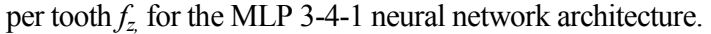

The simulation of the cutting forces was also conducted for the milling cutter helix angle $\lambda s=50^{\circ}$. The parameters of the best MLP networks for modelling the cutting force components $F_{x}, F_{y}$ and $F_{z}$ are shown in Table 3 .

The best network with regards to the cutting force Fx is network 1 (MLP 3-5-1 with 5 neutrons), as training quality was $99,99 \%$ and validation quality $96.87 \%$, the training error was the lowest and was equal to $17.33 \mathrm{~N}$. The cutting force Fy is best modelled with network 1 (MLP 3-4-1 with 4 neutrons), with training quality of $99.99 \%$. Although the validation quality is slightly lower than in network 2 , network 1 exhibits the lowest training error, 3.69 N. In the case of the cutting force component 
$F_{z}$ the best parameters are shown by network 1 (MLP 34-1 with 4 neutrons). Predicted values of the cutting forces for the milling cutter helix angle $\lambda s=50^{\circ}$ obtained from the analysed neural networks are shown in Figs. 8-10.

Table 3. Parameters of the best MLP networks for particular cutting forces, cutting tool helix angle $\lambda s=50^{\circ}$.

\begin{tabular}{|c|c|c|c|}
\hline \multicolumn{4}{|c|}{ Feed force $\boldsymbol{F}_{\boldsymbol{x}}$} \\
\hline Id. & 1 & 2 & 3 \\
\hline Network name & MLP 3-5-1 & MLP 3-4-1 & MLP 3-5-1 \\
\hline Quality (training) [\%] & 99.99 & 99.99 & 99.98 \\
\hline $\begin{array}{l}\text { Quality (validation) } \\
{[\%]}\end{array}$ & 96.87 & 93.56 & 72.44 \\
\hline Error (training) & 17.33 & 19.12 & 30.21 \\
\hline Activation (hidden) & Tanh & Tanh & Tanh \\
\hline Activation (output) & Linear & Logistic & Logistic \\
\hline \multicolumn{4}{|c|}{ Normal to the feed force $F_{v}$} \\
\hline Id. & 1 & 2 & 3 \\
\hline Network name & MLP 3-4-1 & MLP 3-7-1 & MLP 3-4-1 \\
\hline Quality (training) [\%] & 99.99 & 99.98 & 99.98 \\
\hline $\begin{array}{l}\text { Quality (validation) } \\
{[\%]}\end{array}$ & 98.77 & 99.88 & 93.85 \\
\hline Error (training) & 3.69 & 10.55 & 13.33 \\
\hline Activation (hidden) & Tanh & Exponential & Tanh \\
\hline Activation (output) & Linear & Tanh & Linear \\
\hline \multicolumn{4}{|c|}{ Reactive force $\boldsymbol{F}_{z}$} \\
\hline Id. & 1 & 2 & 3 \\
\hline Network name & MLP 3-4-1 & MLP 3-5-1 & MLP 3-4-1 \\
\hline Quality (training) [\%] & 99.98 & 99.97 & 99.97 \\
\hline $\begin{array}{l}\text { Quality (validation) } \\
{[\%]}\end{array}$ & 99.29 & 74.24 & 82.47 \\
\hline Error (training) & 22.76 & 25.4 & 29.24 \\
\hline Activation (hidden) & Tanh & Tanh & Tanh \\
\hline Activation (output) & Tanh & Exponential & Tanh \\
\hline
\end{tabular}

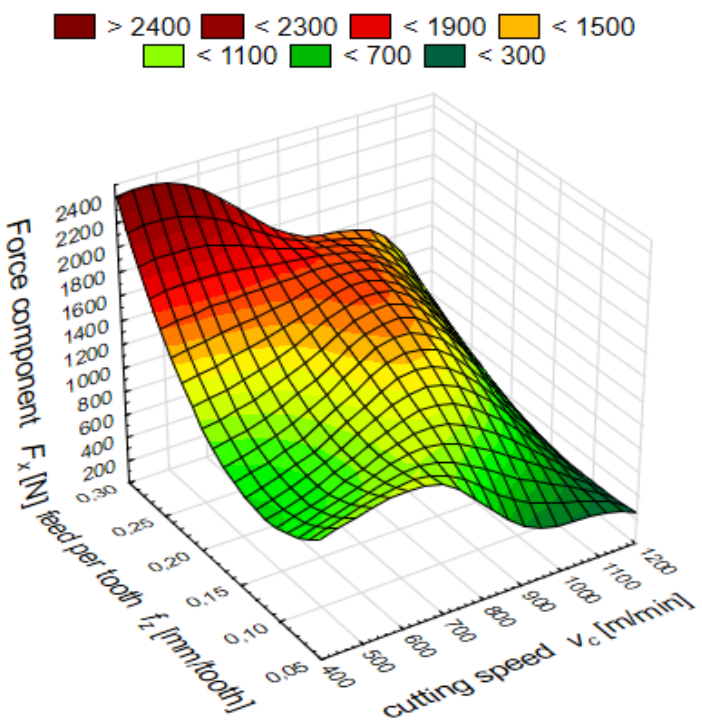

Fig. 8. Results of the cutting force $F_{x}$ simulation for cutting tool helix angle $\lambda s=50^{\circ}$, in the function of cutting speed $v_{c}$ and feed

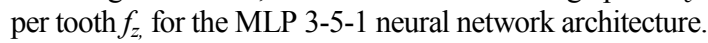

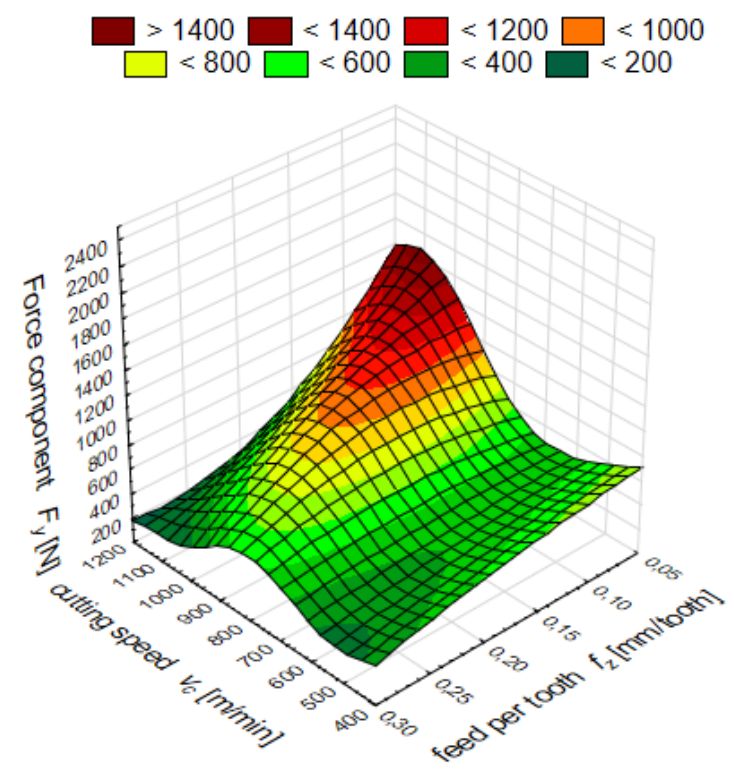

Fig. 9. Results of the cutting force $F_{y}$ simulation for cutting tool helix angle $\lambda s=50^{\circ}$, in the function of cutting speed $v_{c}$ and feed

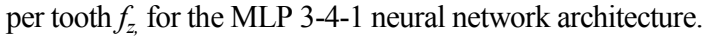

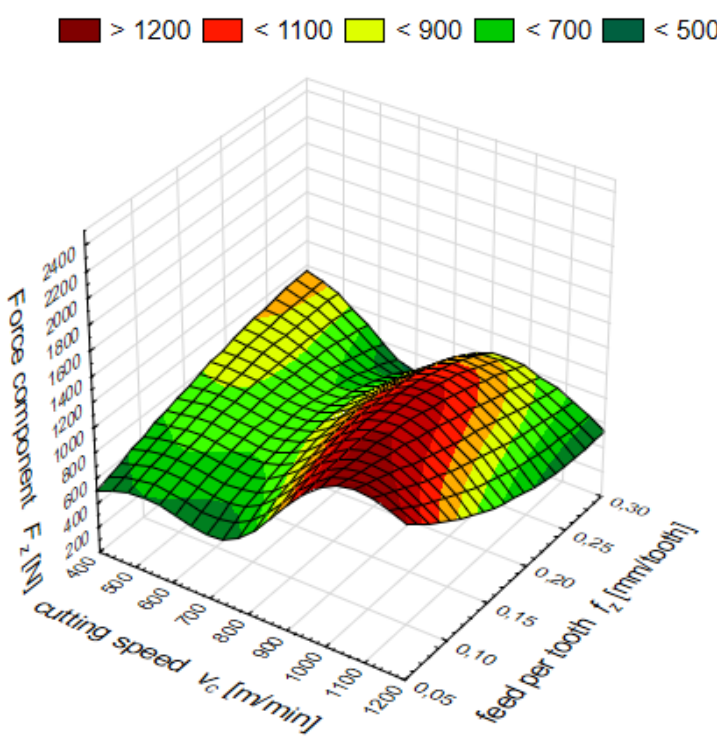

Fig. 10. Results of the cutting force $F_{z}$ simulation for cutting tool helix angle $\lambda s=50^{\circ}$, in the function of cutting speed $v_{c}$ and feed per tooth $f_{z \text {, }}$ for the MLP 3-4-1 neural network architecture.

To present the quality of simulated networks the tables below collate the measured values of the cutting force $F_{x}$ with the values obtained from the networks, $F_{x p}$. The results for the cutting tool helix angle $\lambda s=20^{\circ}$ are show in Table 4, while for $\lambda s=50^{\circ}$ in Table 5 . 
Table 4. The cutting force $F_{x}$ and the forecasted cutting force $F_{x p}$ for given scenarios, $\lambda s=20^{\circ}(\Delta-$ absolute error, $\delta-$ relative error)

\begin{tabular}{|c|c|c|c|c|c|}
\hline $\begin{array}{c}v_{c} \\
{[\mathrm{~m} / \mathrm{min}]}\end{array}$ & $\begin{array}{c}f_{z} \\
{[\mathrm{~mm} / \text { tooth }]}\end{array}$ & $\begin{array}{c}F_{x} \\
{[\mathrm{~N}]}\end{array}$ & $\begin{array}{c}F_{x p} \\
{[\mathrm{~N}]}\end{array}$ & $\Delta$ & $\delta$ \\
\hline 400 & 0.15 & 824.04 & 824.53 & 0.49 & $0.06 \%$ \\
600 & 0.15 & 807.16 & 807.39 & 0.23 & $0.03 \%$ \\
800 & 0.15 & 829.83 & 841.65 & 11.82 & $1.42 \%$ \\
1000 & 0.15 & 680.05 & 684.28 & 4.23 & $0.62 \%$ \\
1200 & 0.15 & 593.98 & 592.13 & 1.86 & $0.31 \%$ \\
800 & 0.05 & 441.70 & 443.1 & 1.38 & $0.31 \%$ \\
800 & 0.10 & 609.40 & 619.5 & 10.11 & $1.66 \%$ \\
800 & 0.20 & 1114.5 & 1115.5 & 0.96 & $0.09 \%$ \\
800 & 0.25 & 1105.8 & 1105.6 & 0.25 & $0.02 \%$ \\
800 & 0.30 & 1100.6 & 1100.3 & 0.36 & $0.03 \%$ \\
\hline
\end{tabular}

Table 5. The cutting force $F_{x}$ and the forecasted cutting force $F_{x p}$ for given scenarios, $\lambda s=50^{\circ}(\Delta-$ absolute error, $\delta-$ relative error).

\begin{tabular}{|c|c|c|c|c|c|}
\hline $\begin{array}{c}v_{c} \\
{[\mathrm{~m} / \mathrm{min}]}\end{array}$ & $\begin{array}{c}f_{z} \\
{[\mathrm{~mm} / \text { tooth }]}\end{array}$ & $F_{x}[\mathrm{~N}]$ & $F_{x \mathrm{p}}[\mathrm{N}]$ & $\Delta$ & $\delta$ \\
\hline 400 & 0.15 & 910.14 & 920.60 & 10.46 & $1.15 \%$ \\
600 & 0.15 & 901.97 & 890.29 & 11.68 & $1.29 \%$ \\
800 & 0.15 & 1176.3 & 1176.1 & 0.15 & $0.01 \%$ \\
1000 & 0.15 & 996.61 & 860.48 & 136.13 & $13.66 \%$ \\
1200 & 0.15 & 581.57 & 581.75 & 0.17 & $0.03 \%$ \\
800 & 0.05 & 800.04 & 800.38 & 0.34 & $0.04 \%$ \\
800 & 0.10 & 1208.5 & 1356.5 & 148.05 & $12.25 \%$ \\
800 & 0.20 & 1862.6 & 1861.4 & 1.20 & $0.06 \%$ \\
800 & 0.25 & 1913.7 & 1912.1 & 1.65 & $0.09 \%$ \\
800 & 0.30 & 1321.1 & 1321.4 & 0.26 & $0.02 \%$ \\
\hline
\end{tabular}

The error of the forecasted data with reference to the actual values of the cutting force $F_{x}$, for cutting tool angle helix $\lambda s=20^{\circ}$, is within the range of $0.02 \% \div$ $1.66 \%$, and for helix angle $\lambda s=50^{\circ}$ the range is $0.02 \% \div$ $13.66 \%$. The analysis of other cutting forces was also performed; the error of the forecasted data referred to the actual values of the cutting force component $F_{y}$ and $F_{z}$, for cutting tool angle helix $\lambda s=20^{\circ}$ is within the range of $0.11 \% \div 4.44 \%$, and $0.19 \%$ and $7.59 \%$ respectively; while for helix angle $\lambda s=50^{\circ}$, the cutting force $F_{y}$ is between $0.17 \% \div 8.04 \%$, and $F_{z}-0.002 \% \div 6.26 \%$.

Simulation results exhibit acceptable error, below $15 \%$. Therefore, the artificial neural network appears to be an excellent solution for simulation of e.g. the cutting forces in milling. It is possible to build effective models of the cutting force components provided that the machining process is properly characterised with such data as machining parameters

These observations imply that artificial neural networks exhibit great potential for non-linear machining processes prediction, such as milling. The presented analysis could be applied to determining the optimal set of parameters and to generate desired cutting forces in milling and provide characteristics of the process without the need for a number of technological tests.

\section{Summary and conclusions}

The conducted analytical and experimental works lead to the following general conclusions:

1. The change of each of the analysed technological parameters: $v_{c}, f_{z}$ and $a_{p}$, and the milling cutter helix angle affect the cutting force components. The feed force $F_{x}$ dominates over other cutting forces.

2. Higher stability and productiveness of milling, as well as lower cutting forces in milling are obtained when machining with a mill cutter of helix angle $\lambda s=20^{\circ}$. The tool $\lambda s=50^{\circ}$ generated higher cutting forces.

3. Simulations of the cutting forces and errors of forecasted data in reference to the actual values measured in tests show that the error for both cutting tool helix angles is within the acceptable range of error. The error for the tool $\lambda s=20^{\circ}$ is lower than for $\lambda s=50^{\circ}$, however the value of error in either of the cases does not exceed $15 \%$.

4. Simulations by means of artificial neural networks enable initial specification of particular technological parameters and forecasted values of the cutting forces in milling.

5. The non-linear relationships between technological parameters and the cutting forces represented by means of neural networks may be used to calculate optimal results of machining, without the need for labourintensive and time-consuming machining tests, which often require conducting costly actual milling operations. 6. A high-precision tool may be devised for modelling phenomena occurring in milling under conditions of incomplete data. The simulation may constitute an important decision-making tool in specifying technological parameters in machine and device component milling applications.

7. Establishing initial machining parameters of milling and forecasted values of the cutting forces by means of artificial neural network simulations increases the productivity and efficiency of the production process, and generates considerable material savings.

8. Artificial neural networks enable the "transfer" from discrete data (input data from the cutting force measurements in milling) to continuous data (simulations enable building diagrams in the form of response surface).

\section{References}

1. Z. T. Fu, W. Y. Yang, X. L. Wang, J. Leopold, 15th Cirp Conf. Model. Mach. Oper. (15th C. 31, 258263 (2015)

2. J. Salguero, M. Batista, M. Calamaz, F. Girot, M. Marcos, Procedia Eng. 63, 735-742 (2013)

3. J. Matuszak, Adv. Sci. Technol. Res. J.(to be published)

4. M. Nejman, D. Śniegulska-Grądzka, K. Jemielniak, Mechanik 8-9, 98-104 (2015)

5. J.-D. Kim, K.-B. Lee, Engineering 2, 788-792 (2010)

6. K. E. Oczoś, Mechanik 5-6, 386-400 (2009) 
7. W. Adamski, Adv. Manuf. Sci. Technol. 34, 73-84 (2010)

8. O. Gziut, J. Kuczmaszewski, I. Zagórski, Adv. Manuf. Sci. Technol. 38, 83-92 (2014)

9. J. Kuczmaszewski, P. Pieśko, Mechanik 10, 846854 (2013)

10. J. Kuczmaszewski, P. Piesko, Eksploat. I Niezawodn. Reliab. 16, 37-41 (2014)

11. I. Danis, F. Monies, P. Lagarrigue, N. Wojtowicz, Int. J. Adv. Manuf. Technol. 84, 1801-1820 (2016)

12. P. Kazemi, M. H. Khalid, J. Szlek, A. Mirtic, G. K. Reynolds, R. Jachowicz, A. Mendyk, Powder Technol. 301, 1252-1258 (2016)
13. M. Kulisz, I. Zagórski, A. Semeniuk, Appl. Comput. Sci. 12, 49-58 (2016)

14. B. H. Wu, X. Yan, M. Luo, G. Gao, Chinese J. Aeronaut. 26, 1057-1063 (2013)

15. PN-EN 1753:2001Magnez i stopy magnezu - Gąski i odlewy ze stopów magnezu

16. Świadectwo kontroli jakości - stop magnezowy AZ91, www.stanchem.pl(2014)

17. https://www.dynacast.com/az91d

18. A. Skoczylas, K. Zaleski, Mechanik 8-9, 311-319 (2015)

19. http://www.statsoft.pl/Portals/0/Downloads/Sieci\%2 0neuronowe.pdf 